\title{
Visita de Juan Pablo II a Cuba Reflexiones desde El Salvador
}

\section{Juan Pablo II y Fidel Castro}

La visita de Juan Pablo II a Cuba y su encuentro con Fidel Castro ha sido un acontecimiento histórico, impensable hace sólo unos pocos años. Tampoco ha acontecido al acaso, sino que ha estado bien preparado, tanto por lo que toca al fondo de los problemas (lo que se expresaba en la absoluta libertad con que habló Juan Pablo II y la absoluta normalidad con que escuchaba Fidel Castro), como por lo que toca a la organización externa: las eucaristías, la música de buenos e inmensos coros, la participación multitudinaria. Es cierto que la situación ha sido dura para la Iglesia cubana, pero en nada se parecía aquello a "una Iglesia salida de las catacumbas".

$\mathrm{Y}$, sin embargo, han tenido que pasar cuarenta años para que ocurra un acontecimiento semejante. Los personajes centrales en este encuentro, Juan Pablo II y Fidel Castro, han aportado para hacerlo posible su personalidad carismática y sus firmes convicciones. Un vespertino los llamó "Ios dos últimos cruzados del siglo XX". También don Pedro Casaldáliga, con humor y cariño, los llamó "testarudos y fundamentalistas". Pero con todo, han sido los dinamismos históricos los que en definiltiva se han impuesto. Como diría Ellacuría, ha habido algo de "fatalismo histórico" en este encuentro, o quizás sea mejor decir que ha habido algo de "providencia histórica" para ver a Juan $\mathbf{P a}$ blo y a Fidel Castro darse la mano y sonreír. Y es que los procesos, originados por seres humanos, acaban llevándolos también a ellos.
Sobre este viaje papal ha habido más expectativas y curiosidad que análisis $y$, por eso, para comprender su significado y sus posibles consecuencias, es necesario tener en cuenta la larga historia que lo ha precedido. Las cosas, en efecto, comenzaron de manera muy distinta después del triunfo de la revolución. En 1959, ni la revolución ni la Iglesia cubana estaban preparadas para los cambios que iban a ocurrir.

La Iglesia cubana era hija de su tiempo y no tenía un Vaticano II, y menos un Medellín, para entender siquiera qué relación podría tener la fe cristiana con una revolución social. Dios y justicia, Jesús y liberación de los pobres, un Cristo crucificado por defenderlos y denunciar a sus opresores, y un Cristo resucitado, esperanza a las víctimas, no era la teología de la época. Como en muchas otras, también en la Iglesia cubana, la fe miraba más al más allá, y en el más acá se contentaba, en lo social, con la caridad y la limosna. Que Dios quisiera una transformación radical del mundo de pobreza e injusticia - el reino de Dios- no entraba en el horizonte. De esta forma se mantenía una paradoja que con ironía se formuló de esta manera: en el siglo XVI la Iglesia católica "dejó la libertad en manos de herejes", nuestros hermanos protestantes, y en el siglo XIX "dejó a los pobres en manos de ateos", nuestros hermanos marxistas.

Por su parte, la revolución tampoco entendió lo religioso como dimensión esencial del ser humano, dimensión que va más allá de la organización eclesiástica. También hija de su tiempo, la revolu- 
ción comprendió la religión según los manuales dogmáticos marxistas como opio y como anticientífica. Entendió bien que el ser humano no debe ser anticientífico, pero no entendió que siendo sólo científico no tiene por qué ser humano. Surgió, pues, un conflicto entre revolución e Iglesia que se expresó al principio a nivel ideológico, pero que pronto se tradujo en conflicto político, es decir, en conflicto de poderes entre la Iglesia católica, la institución más antigua de Cuba con su poder cultural e ideológico y el nuevo poder revolucionario.

Poco a poco hubo cambios. En la Iglesia cubana se notó, aunque levemente, el influjo de Medellín que comenzó a no separar lo que Dios había unido desde siempre: la fe y la justicia. Así, un año después, en 1969, denunció por primera vez "la injusta situación de bloqueo" contra Cuba de parte Estados Unidos que había comenzado en 1961. En 1986, el Encuentro Nacional Eclesial Cubano (ENEC) hizo una presentación serena de la situación nacional y eclesial, reconoció lo que son valores de la revolución y de la sociedad socialista, e -inauditamente- dijo que veía en esos valores la acción de Dios. Pero no se inhibió en la denuncia. En 1993, los obispos señalaron que "deherían erradicarse algunas políticas irritantes" y mencionaron estas cinco: (1) El carácter excluyente e irritante de la ideología oficial. (2) El excesivo control del Estado sobre las personas. (3) Las limitaciones impuestas a ciertas libertades y a la idea misma de libertad. (4) El alto número de prisioneros por motivos políticos. (5) La discrimación por ideas políticas y religiosas...

También hubo cambio de parte de la revolución - ciertamente de parte de Fidel Castro, más idealista que otros miembros duros del partido-, y el desencadente fue también Medellín, con la teología de las liberación, el ejemplo de miles de cristianos comprometidos y los innumerables mártires que dieron su vida por la justicia: la religión no tenía ya por qué ser opio del pueblo, los cristianos habían mostrado que amaban a los oprimidos y se comprometían con su liberación, que su Dios es un Dios de justicia... En Chile (en tiempo de Allende) y en Jamaica, Fidel Castro habló de lo posible y deseable de una convergencia estratégica entre cristianos y revolucionarios. Esto se fue traduciendo en mayor libertad religiosa, sancionada en el IV Congreso del partido comunista en 1991. (Cuando pase el tiempo y haya más perspectiva histórica, incluso, quienes ahora lo combaten, agradecerán a Medellín, a la teología de la liberación y a los mártires, que ellos desbloqueron el camino hacia Dios a muchos que buscaban la justicia, y no veían en Dios un aliado porque no lo veían en la Iglesia).

Junto a estos cambios internos se dieron cambios en la geopolítica mundial: con la caída del Este una Cuba socialista era simplemente inviable. El inhumano bloqueo del gobierno de Estados Unidos acabaría por ahogar al país. En esa situación - curiosamente- Fidel Castro, aislado, necesitaba del Papa, de donde podía venir la salvación. Para la Iglesia era una ocasión única de mostrar su liderazgo y su poder en el mundo, a lo que es proclive la actual administración vaticana. Los cambios internos en la revolución y la Iglesia, y la coyuntura han hecho, pues, posible este encuentro.

En el aeropuerto, Fidel Castro mostró respeto y admiración por el Papa y agradeció su venida. La ocasión se convertía en la mejor plataforma —más importante, incluso, que Naciones Unidas - para recordar los logros de la revolución y denunciar con fuerza el bloqueo económico. Los ojos de todo el mundo estaban en el aerpuerto de La Habana, y el Papa - alabado por los países occidentales por su decidido anticomunismo- estaba en su favor. En la respuesta, Juan Pablo II trató con respeto y afabilidad a Fidel Castro, y expresó, como en germen, lo que desarrolló después: "que Cuba se abra al mundo y que el mundo se abra a Cuba".

En los días siguentes sus palabras fueron subiendo de tono. En presencia de altos gobernantes, el Papa denunció y pidió poner remedio a los males del país. Exigió libertad para la población, observancia de los derechos humanos, libertad para los presos políticos, libertad de educación, cambios radicales en la familia con una durísima condena del aborto. Condenó el ateísmo de estado y pidió libertad para la Iglesia. No cabe duda de que el Papa dijo con su valentía acostumbrada $-y$ con la libertad que le había garantizado Fidel Castrotodo lo que veía mal en Cuba. (De hecho no ha hablado con esa dureza a otros líderes de Occidente, a Ronald Reagan, por ejemplo, corresponsable de terrorismo de estado en El Salvador y Nicaragua).

Esas denuncias fueron las más repetidas, pero también hubo otras en sentido contrario. Una de ellas, pensando en la juventud sobre todo, es la de 
no caer en la pseudocultura que ofrecen de fuera y lleva al consumismo y la trivialización de la existencia. La segunda, la más insistente, fue la condena del bloqueo económico de Estados Unidos. En el aeropuerto al despedirse dijo estas fuertes palabras: es "injusto e inmoral". Por último hizo una denuncia universal a la configuración económica actual. En su última homilía en La Habana criticó el neoliberalismo capitalista que subordina la persona humana a las fuezas ciegas del mercado, gravando desde sus centros de poder a los países pobres con cargas insoportables. Y denunció también que a estos países se les impongan programas económicos insostenibles, que enriquecen a unos pocos a costa del empobrecimiento de muchos.

El Papa habló, pues, a todos con toda claridad. En Cuba ocurrió una especie de catarsis y la visita fue un signo de esperanza. Sin embargo, fue también notable que en ningún momento se generó un ambiente tenso. Fidel Castro, se puede discutir si por devoción o necesidad, se comportó con

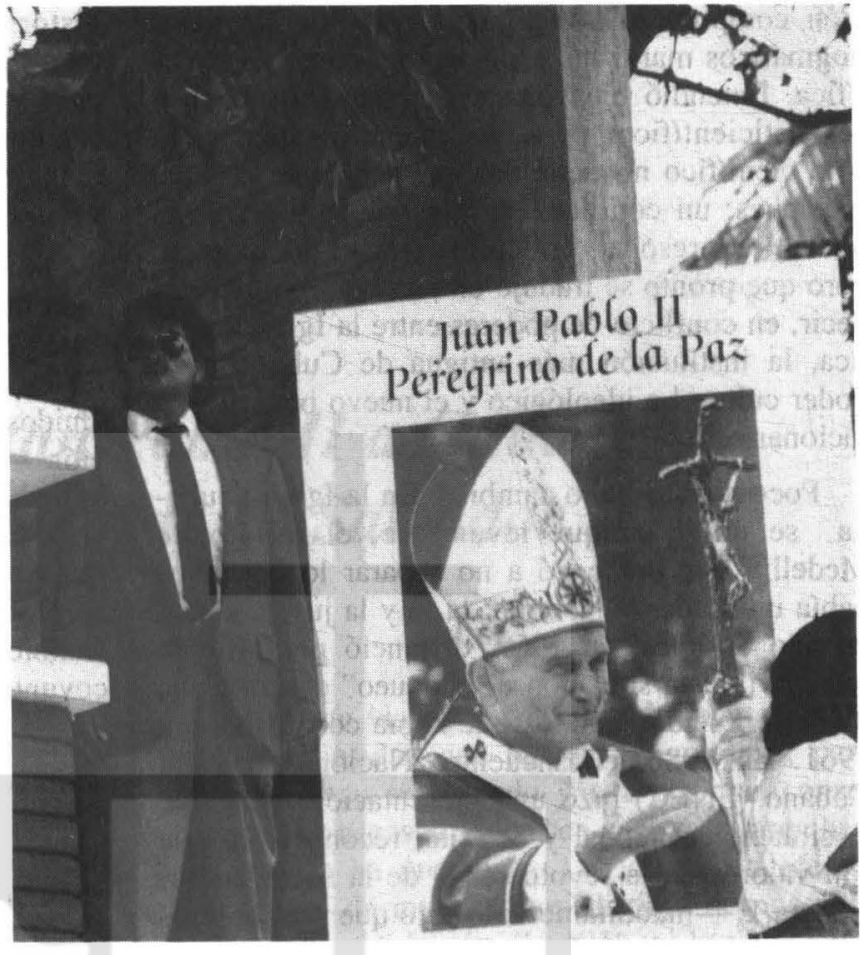
Juan Pablo II, todo el tiempo, con exquisita corrección y afabilidad. Estuvo entre los presentes para escuchar su discurso en la universidad, y en la misa de La Habana parecía disfrutar dando la paz a obispos, religiosas y laicos. Juan Pablo II, por su parte, se mostró respetuoso con los personajes y símbolos de la revolución. En el avión habló con respeto y cariño del che Guevara. Al final de la misa, en la plaza de la revolución, tuvo el gesto inusual de bajar a saludar a Fidel. Y en el aeropuerto caminaron juntos hasta el avión.

¿Quién ganó?, es la pregunta que se oye estos días. Pero, aunque comprensible y aunque ambos son personajes a quienes les gusta ganar, la pregunta es improcedente. La pregunta es más bien qué ganó el pueblo cubano, los hombres y mujeres que viven, esperan y sufren en Cuba, qué ha ganado el mundo de los pobres en los cinco continentes, cómo utilizar este encuentro para poner al mundo en una direccion más humana y justa.

En Cuba ya se han dado algunos pasos en el camino de la reconciliación, pero ésta no debiera ser entendida como reparto de poder entre Iglesia y revolución, sino como convergencia de los me-

jores ideales y logros revolucionarios y de lo mejor de la Iglesia, que es el Evangelio de Jesús y sus testigos en la historia. No es un presidente y un papa lo que está en juego, sino lo que ambos pueden simbolizar de bueno y humanizante.

Quizás exırañe que hablemos así de las posibilidades de una revolución, pero sería miope no hacerlo. La democracia, la libertad ciudadana y otros logros que el Papa exigió en Cuba, en su día fueron logros revolucionarios (aunque la Iglesia hasta prácticamente el Vaticano II haya condenado las revoluciones o las haya mirado con desconfianza). La idea socialista, el compartir justamente los bienes, "la prioridad del trabajo sobre cl capital" (repetido por Juan Pablo II) históricamente son frutos de ideas y revoluciones socialistas. Y también sería injusto olvidar los logros de Cuba en el campo social, salud, educación, muy superiores a los de todos los países de América Latina... Los fallos reales, algunos terribles, del socialismo real, los acaba de denunciar el papa con toda claridad. Pero sería injusto y empobrecedor ignorar lo que hay de mística en el socialismo, si en verdad se busca reconciliación en Cuba. y si se buscan soluciones 
humanas en nuestros países. En este sentido, es una pena que Juan Pablo II no hiciera alguna alusión a los logros cubanos para animar lo bueno.

La Iglesia, por su parte, tiene mucho que aportar. Puede ofrecerse como lugar de encuentro de todos: cristianos, hombres y mujeres de otras religiones, abundantes en Cuba, no creyentes. Pero sobre todo puede ofrecer la mística del Evangelio, de la honradez y la verdad, de la compasión y la misericordia, de la acogida al otro, aunque sea diferente. Esto es utopía, claro está, pero ése es el verdadero y auténtico poder de la Iglesia. Y si también reconoce, sin masoquismo, pero con honradez, sus limitaciones y pecados, ahora y a lo largo de la historia, como los debe reconocer la revolución, se hará más fácil la reconciliación. Quizás por razones comprensibles, Fidel lo recordó en su discurso mientras que Juan Pablo II lo silenció.

En Cuba ya se ha superado la "demonización" del otro, pero quizás hay que superar todavía indicios de maniqueísmo, como si todo lo bueno estuviese en una parte y todo lo malo en otra (aunque en ello insiste, interesada e injustamente, el mundo occidental). Cómo superen los revolucionarios el maniquismo, es una cosa. Pero los cristianos creemos que toda la creación, no sólo la Iglesia, es obra de Dios; que en todas partes, no sólo en la Iglesia, hay semillas suyas (como decían los primeros cristianos). Desde la fe cristiana, la reconciliación es encontrarse en la verdad, la justicia y la compasión de Dios con todos, especialmente con los más pobres de este mundo.

¿Y las reaciones? Mencionemos sólo algunos ejemplos importantes. Guatemala anunció que pronto reanudaría relaciones con Cuba. Estados Unidos urgió a Fidel Castro a cumplir lo que había exigido el Papa, haciendo oídos sordos - hipócritamente - a la condena papal al bloqueo. Fidel Castro mostró su satisfacción, orgullo y agradecimiento por el éxito de la visita del Papa y anunció la liberación de 299 presos -aunque Estados Unidos, de nuevo, se quejó de que no serían liberados todos los que estaban en la lista que había entregado el cardenal Sodano. Juan Pablo II, una vez en Roma, sorprendió con una declaraciones que, la verdad, no sonaron muy oportunas: expresó su deseo de que ocurriese en Cuba lo mismo que ocurió en Polonia tras su primera visita.

\section{Las exigencias de la visita para El Salvador}

En El Salvador, como era de esperar, en noticias y declaraciones de los políticos se impuso, en general, la perspectiva oficialista del mundo occidental. El arzobispo apenas si dijo gran cosa y recalcó, como suele hacerlo, que la visita del Papa era pastoral y espiritual. Quien sí enmarcó la visita adecuadamente fue Monseñor Rosa, pues habló sobre las consecuencias para nuestro país. Así, el domingo 8 de febrero, en su homilía y la conferencia de prensa después de la misa, Monseñor Rosa relacionó la visita con lo ocurrido en el país.

En efecto, según informaciones de prensa, el 2 de febrero, dirigentes de los sindicatos de Obras Públicas, ANDA, Ministerio de Salud, ex ANTEL y UNTS, se habrían tomado la iglesia San Francisco en San Salvador, como protesta por los despidos de sindicalistas. Según las mismas fuentes, los sindicalistas habrían manifestado que su estancia en el templo era una "toma pacífica", mientras que el arzobispo, Fernando Sáenz Lacalle, expresaba que los que participan en la toma de iglesias son merecedores de la excomunión. "No estamos de acuerdo con la toma, sea pacífica o no. Estamos en un ambiente de libertad donde toda la gente puede manifestarse. Por lo tanto, no se deben manipular los edificios sagrados porque se atenta contra la libertad del pueblo de tener acceso a las iglesias. Hay que tomar en cuenta que el fin no justifica los medios". También el Presidente de la República pidió a los trabajadores que recapacitaran: "Esperamos reflexión y que no se dejen instrumentalizar".

Monseñor Rosa Chávez aclaró los hechos. En primer lugar, no hubo toma del templo ni daños en las paredes, sino que hubo una actividad de tres horas frente al templo, sobre la cual los sindicalistas ya habían dialogado con él. Pero lo importante es la reflexión. Monseñor Rosa recalcó que se están violando los espacios y se está generando una especie de cultura de la sordera. "Está queriéndose ocultar que hay problemas serios en el campo laboral, en la dinámica de la globalización, en la dinámica de la privatización". Y en este contexto se refirió al mensaje de Juan Pablo II en su visita a Cuba.

"Resurge en varios lugares una nueva forma de neoliberalismo capitalista que subordina la persona humana y condiciona el desarrollo de los 
pueblos a la fuerza ciega del mercado, gravando desde sus centros de poder a los países menos favorecidos con cargas insoportables. De este modo se asiste al enriquecimiento exagerado de unos pocos a costa del empobrecimiento creciente de muchos, de forma que los ricos son cada vez más ricos y los pobres cada vez más pobres".

Y como reflexión personal añadió. "No olvidemos este análisis a la hora de juzgar las inquietudes que encontramos entre los trabajadores. ¿Cómo queremos que no protesten si se les niegan los más elementales derechos humanos?". Comentó también que la prensa salvadoreña se concentró en lo que iba a pasar con Fidel tras la visita, pero no se preguntó, a la luz del mensaje papal, qué nación tiene que surgir en El Salvador.

"Ese mundo nuevo lo necesitamos en El Salvador. Por tanto, el mensaje social del Papa es muy importante para nosotros y deberíamos alegrarnos de que tan cerca de nuestras fronteras esté recordando cómo se construye el futuro. Dios quiera que retomemos ese mensaje del Papa y lo analicemos ahora que estamos con la gran oportunidad de poder discutir, dialogar, buscar consensos en torno a qué país queremos en el campo económico, en el campo político, en el campo cultural, en el campo social, en el campo de justicia. Hay tanto que cambiar y deberíamos ser un poquito más activos y más propositivos".

Dijimos antes, al analizar la visita, que no hay que caer en triunfalismos ni maniqueísmos, como si todo lo bueno estuviera de un lado y todo lo malo del otro. Bien está que la Iglesia le diga a Fidel Castro lo que hace mal para que lo haga bien. Pero, para hacerlo con honradez y credibilidad, también la Iglesia debe dejarse decir lo que hace mal para hacerlo bien, lo cual no ocurre con facilidad pues la Iglesia es proclive al triunfalismo y a veces a la prepotencia sacral.

Juan Pablo II no tocó estos temas en Cuba, y la ocasión no lo hacía verosímil. Pero con motivo del Jubileo del año 2000 ha insistido en que hay que "pedir perdón". Por ello, más allá de la visita y para no caer en triunfalismos que nada bueno producen, preguntémonos no sólo en qué tiene que cambiar la revolución, sino en qué tenemos que cambiar como Iglesia. Para ponerlo en forma operativa - de modo que pedir perdón se convier- ta en hacer el bien- preguntémonos, como hemos dicho otras veces, por "las deudas de la Iglesia con los pobres".

Cómo se deba hacer esto en Cuba es cosa que esa Iglesia debe analizar. Aquí en El Salvador, donde ha habido una Iglesia de los pobres, y que sobrevive con gran mérito en bastantes lugares, aunque no como antes, podemos hacer las siguientes sugerencias.

(1) En un país en oscuridad, confundido y desorientado, la Iglesia le debe al pueblo orientación sobre lo que ocurre. En el caso reciente de la corrupción de las financieras, por ejemplo, la jerarquía no se hizo presente enmarcando los acontecimientos en un contexto evangélico. No orientó sobre cosas fundamentales: por qué protestan ahora y salen a las calles los ricos y pudientes que han estado callados ante crímenes y masacres; si a los ricos se les defrauda, qué ocurrirá a los pobres; qué decir de ricos opulentos y corruptos que han estado cercanos a la Iglesia. Y junto a esta orientación en coyunturas importantes, le debe al pueblo un análisis serio de las causas estructurales de los males: globalización, neoliberalismo, modernización, como hacía Monseñor Romero en sus cartas pastorales. Y le debe también la denuncia, analizada, de los males que se encubren en el funcionamiento del sistema de justicia, de la policía nacional...

(2) La Iglesia le debe al pueblo poner su fuerza social en favor de todo lo que sea organización, movimientos, comunidad popular. Al menos, debe retomar la idea de lo que fue realidad en tiempos pasados, aun con sus errores, y proclamar que la comunidad, ideal cristiano y salvadoreño, es lo que le hará prosperar en verdad, y no el individualismo (unido al consumismo, hedonismo, indeferentismo), que es el componente mal llamado cultural de la globalización.

(3) Sobre todo, la Iglesia le debe al pueblo la esperanza. No hay recetas, pero hubo un tiempo en que la Iglesia daba esperanza al pueblo. Eso sí, con encarnación, con verdad, con fortaleza, con solidaridad con él hasta el martirio.

En este país hemos tenido una Iglesia de los pobres. Fueron tenidos muy en cuenta en el interior de la Iglesia, pero además se convirtieron en principio inspirador de su doctrina y su acción pastoral. ¿Qué deudas tiene la Iglesia -en su interior- con los pobres? Veamos. 
(1) La Iglesia debe a los pobres el repensarse a fondo desde ellos. La mayoría de los salvadoreños y salvadoreñas son pobres, y religiosamente se organizan hoy, muchos de ellos, alejados de la Iglesia institucional: los evangélicos (mejor llamarles así que sectas), varios de los movimientos eclesiales. Otros, pobres también, han sido alejados por la Iglesia (comunidades de base, la antigua Iglesia popular). Aunque mayoritariamente la Iglesia esté entre pobres, en su pensamiento doctrinal, litúrgico, canónico, teológico, no se piensa desde ellos, en cuanto pobres históricos, empobrecidos y oprimidos. Simbólicamente, miembros de la jerarquía aparecen en público junto a gobernantes, militares y oligarcas.

(2) La Iglesia debe a los pobres el aglutinarse alrededor de ellos, lo que antes se hacía en semanas de pastoral, difíciles y conflictivas, pero necesarias y provechosas. Es necesario preguntarse y aprender de ellos, para devolverles en palabra evangélica y teológica su propia palabra, lo que antes se hacía con las encuestas que se pasaban a los pobres antes de escribir cartas pastorales (recuérdese la cuarta carta pastoral de Monseñor Romero). Y en este contexto, la Iglesia debe a los pobres sacerdotes, religiosas, obispos, teólogos y teólogas, seminarios, centros de formación, publicaciones... que hayan hecho, comprobadamente, más allá de palabras vacías, una opción por ellos.

(3) La Iglesia debe a los pobres el recuerdo de sus mártires, es decir, devolverles en muerte la dignidad que los poderosos les arrebataron en vida. Y por lo que toca a los supervivientes, dar consuelo a familiares y amigos, dar ánimo a los que quieren seguir sus huellas. Y les debe también una llamada seria a sus victimarios a la conversión, para que no se piense que "aquí no ha pasado nada". Qué hagan políticos, militares y oligarcas con los mártires es una cosa. Pero la Iglesia no puede confundir el perdón con el olvido, el amor con la impunidad.

(4) A las mujeres, especialmente, la Iglesia les debe reparación. Esposas, compañeras y madres sufridas, las que impiden que el país caiga en el caos; religiosas abnegadas y serviciales, que tantas veces mantienen la credibilidad que pierde una Iglesia masculinizada... Las cosas no pueden seguir así en la Iglesia con la mujer. No es justo, en términos de derechos humanos. No es evangélico, en términos de Jesús.

(5) Por último, la Iglesia debe a los pobres la fe. Cómo hacer presente a Jesús en palabra y obra. A un Jesús que no comienza juzgando a los pobres por sus obras, sino que las quiere por sus deventuras. A un Jesús que no los considera como seres inferiores a quienes hay que ayudar, sino como personas con valores y capacidades que pueden poner a producir. Jesús, a diferencia de lo que la Iglesia hace a veces, no se da crédito a sí mismo, ni se hace propaganda después de una curación, sino que dice al enfermo o a la enferma: "Vete en paz. Tu fe te ha curado".

Estas reflexiones pueden hacerse a propósito del Jubileo o del comienzo de la cuaresma o de muchas otras cosas. Las hacemos con ocasión de la visita del papa a Cuba porque es un acontecimiento importante. Y lo peor que puede ocurrir en esos casos es trivializarlos, quedarnos como meros espectadores, apostar "a ver quién gana", o regodearnos de que, por fin, ha caído el comunismo.

Eso lo pueden hacer otros, pero los cristianos, en estas ocasiones, debemos preguntarnos también por nosotros y por lo que tenemos que hacer. Y de esa forma, más allá de triunfalismos, podemos ayudar al pueblo y a la Iglesia de Cuba, de El Salvador y de otras partes.

Jon Sobrino 